\title{
Assessing adaptation to extreme weather events in Europe-Editorial
}

\author{
Reinhard Mechler • Zbigniew W. Kundzewicz
}

Received: 13 August 2009 /Accepted: 4 July 2010 /

Published online: 7 September 2010

(C) Springer Science+Business Media B.V. 2010

\section{Disasters and climate change: an "extreme" adaptation challenge?}

The present Special Issue of the journal Mitigation and Adaptation Strategies for Global Change reviews impacts, risks, and adaptation to extreme weather events in Europe under global and climate change. Most of the multi-disciplinary material of this Special Issue originates from work carried out by an international group of researchers for the ADAM (Adaptation and Mitigation Strategies) Integrated Project of the 6th Framework Programme of the European Union.

The escalating increase in disaster losses from floods, droughts, and other climate-related disasters both in developed and developing countries has become a major concern. On a global scale annual material damage from large weather events has increased 8-fold between 1960s and 1990s, while the insured damage has risen even stronger (17-fold in the same interval), yet loss of life has been brought down considerably (Mills 2005). There are several factors that may explain changes in hydro-meteorological hazards and their impacts. The principal three categories of factors read: changes in socio-economic systems (e.g. land-use change, increasing exposure and damage potential, changing risk perception);

R. Mechler

International Institute for Applied Systems Analysis (IIASA),

Laxenburg, Austria

R. Mechler

Vienna University of Economics and Business,

Vienna, Austria

Z. W. Kundzewicz $(\bowtie)$

Institute for Agricultural and Forest Environment,

Polish Academy of Sciences (PAS), Poznań, Poland

e-mail: kundzewicz@yahoo.com

Z. W. Kundzewicz

Potsdam Institute for Climate Impact Research,

Potsdam, Germany 
changes in terrestrial systems (e.g. land-cover change-urbanization, deforestation); and changes in climate and atmospheric system. Increase in exposure results from the growing wealth of the society (increasing damage potential) and economic activities increasing the threat (e.g. economic development of flood-prone areas). But this alone does not fully interpret the increase in damage, which has been stronger than population or economic growth (Mills 2005).

The aim of this Editorial is to introduce the logic and the structure of the whole Special Issue of Mitigation and Adaptation Strategies for Global Change.

There is mounting evidence of a significant climate-change signal in natural disaster events, for example, extreme precipitation at mid and high latitudes, extreme floods and droughts (Parry et al. 2007). Even if developing countries are particularly vulnerable to current and future climate variability, also Europe is increasingly concerned about the adverse impacts of climate variability and climate change.

Since the cost of damages caused by natural disasters increases, ways of counteracting are being searched and researched. The two principal approaches are: mitigation of climate change (curing the sources of the malady) and adaptation to climate change impacts (curing the symptoms of the malady). The third stance- "business-as-usual", "do-nothing" or "wait-and-see", postponing any action until robust and less uncertain information has been gathered, although not vanished completely from the debate, is increasingly recognized as leading to an important loss of opportunity.

Irrespective of future changes, already today weather-related disasters pose substantial burdens for households, businesses, and governments, and adaptation has to start now, reducing current and future vulnerabilities to changes in climate at the local and regional levels. The good news is that processes, models and data exist to tackle the management of disaster risks. Although the assessment of adaptation to extremes and their impacts is complicated by the inherent uncertainty, and weather can only be reliably forecast a few days into the future, weather extremes are predictable in probabilistic terms, such as the 100 year flood (an event being exceeded with an average recurrence period of 100 years, or an annual probability of $1 \%$ ). We build on this and suggest that important progress can be made in modelling extremes in a risk-based, more geographically explicit manner. Such analysis is increasingly possible as recent innovations and improvements in modelling techniques and data can be harnessed from the climate change and natural hazards modelling communities. This can result in a better and more consistent assessment of natural disaster risk as a function of a geophysical signal, socioeconomic drivers and vulnerability accounting for the inherent aleatoric (chance) variability of natural hazards. In case of adaptation to floods, one may select a strategy of protection (as far as technically and financially feasible), or a strategy of "living with floods" (acknowledging that complete protection is not possible), or a strategy of retreat (relocation from unsafe river flood plains to safe areas). Flood preparedness systems can be built that control the water masses (by storing them in artificial reservoirs or constraining them between embankments) or reduce the vulnerability and increasing the resilience of human systems. Finally, risk sharing mechanisms such as through insurance or the European Solidarity Fund exist.

The bad news is that there is a lack of consistent and risk-based estimates accounting for hazard, exposure and vulnerability in a dynamic sense. Studying risk of weather extremes is difficult, as there is a wider gap in the knowledge of risks from extreme weather events (and the contribution of climate change to their frequency and intensity) than from other climate impacts. The extent to which current and recent weather-related disaster losses can be attributed to a changing climate is controversial, due to a high 
amount of natural variability, uncertainty and multi-factor context. Finally, a great deal of knowledge exists on the risks (exposure, sensitivity and impacts) from extreme weather, but there has been less information on economic vulnerability and associated follow-up effects as well as on the impacts, costs, benefits and challenges of efficient and equitable adaptation.

This is where this Special Issue on ADAM research makes a significant contribution. One key research ambition of this multi-partner project has been to contribute to the fundamental question underlying the post-2012 negotiations: What will be the economic costs and benefits of adapting to unmitigated $4^{\circ} \mathrm{C}$ global warming (above the pre-industrial level) versus a $2^{\circ} \mathrm{C}$ warming implying strong and effective mitigation? By quantifying current and future risks of extreme weather in the EU, and identifying the costs of structural/technological and other paths for adapting to extremes (retreat and living with the risks being other paths), the material contained in this Special Issue provides an important piece of the puzzle underlying this post-2012 question.

The research on adaptation to extremes reported here focussed on assessing current and future disaster risks and identifying promising adaptation options. Comprehensive probabilistic maps of flood and drought risks across the EU, combining estimates of hazard, vulnerability and exposure are provided. These calculations remain uncertain, but they mark the beginning of an innovative risk management approach that is expected to have great influence on national and local policymakers preparing for climate change (cf. Mechler et al. 2010a). We find many regions in Central and Eastern Europe to be hotspots for flood risk, and regions in Southern Europe for drought and heat stress to agriculture. Floods are likely to worsen over much of Europe, yet due to a lack of localised projections from climate models we consider robust future risk projections for a specific site of interest not possible. In contrast, we feel more confident in projecting drought and heatwave risk as a function of changes in broader-scale average climate. Although conditions are likely to worsen across Southern Europe, effective adaptation seems at least partially possible. Yet regional heterogeneity in risk and response will continue leading to climate change "winners" and "losers." Focusing on governments' risks, we calculate large weather-related contingent liabilities, particularly in key flood hot spots. We find that substantial flood risks ("hidden" disaster deficits) coupled with adverse fiscal conditions may lead to significant additional stress and little flexibility to fund other emergent projects. Our work also led to an adaptation 'catalogue': an inventory of practical adaptation options and associated enabling institutional frameworks. With respect to EU policies, we see adaptation to represent a new priority for policy makers. This requires a change in attitude relative to the political vision, but also a change in terms of priorities. In a complex financial framework such as that governing the European Union, a shift in priorities, in order to be effective, must correspond to a shift in budgetary allocations.

\section{Assessing risks and adaptation-review of topics}

The approach to assessing climatic risks and their economic consequences presented in this Special Issue is novel, as authors build on estimating probabilistic and spatially explicit climatic risks today and project those into the future, with and without adaptation. This issue discusses advantages and constraints of this approach, as well the basics of the economics of disaster risks and adaptation, the framing and mainstreaming of adaptation, and specific adaptation options for the EU. The present Special Issue of the journal 
Mitigation and Adaptation Strategies for Global Change contains 11 papers (including the present Editorial), grouped in three complementary parts:

Part I - Physical risk and adaptation;

Part II - Economic analysis of risk and adaptation; and

Part III - Adaptation and policy

Part I of this issue, devoted to physical risk and adaptation consists of five papers pertaining to different sectors and systems. The two first papers deal with the risk of river floods. Lugeri et al. (2010) discuss a methodological framework for river flood risk assessment at European scale and offer evaluation of the present status. Kundzewicz et al. (2010) tackle projections for future time horizons, reviewing river flood risk and adaptation in Europe in a changing climate. Further, Moriondo et al. (2010) attempt to assess impacts and adaptation to climate change and variability (including drought and heat waves) in agriculture. The next contribution, presented by Schelhaas et al. (2010) deals with the European forestry sector, assessing risk and adaptation options to forest fires and windstorm. Finally, Hinkel et al. (2010) review coastal systems, assessing risk and adaptation to sea level rise and storm surge.

Part II contains three papers concerned to the economic analysis of risk of and adaptation to extreme weather events. Aakre et al. (2010) identify current and improved roles for the public and private sectors in the management of extremes and adaptation. They focus on risk financing options (such as insurance) and suggest ways to improving the role of the public sector. In a next paper on modelling economic risk and adaptation by Mechler et al. (2010b) the state of the art regarding economic analysis of adaptation is reviewed and modelling approaches presented which are developed for studying private and public sector, as well as autonomous and planned adaptations. Aaheim et al. (2010) study a case of landslide risk on a local scale assessing this specific risk with the purpose of identifying efficient adaptation opportunities and challenges.

The final Part III deals with policy issues. Framing and assessing adaptation is the topic of the contribution by McEvoy et al. (2010). Finally, Hochrainer et al. (2010) discuss adaptation and risk financing by means of the EU Solidarity Fund, which is a pan-European solidarity mechanism established in the European Union after the dramatic Central European flooding of August 2002.

\section{Physical risk and adaptation in systems and sectors}

The present Special Issue deals with a number of categories of extreme weather events, such as floods and landslides, droughts and heat waves, wild fires, gale winds, and coastal climate risks, and their impacts. However, it does not cover the entirety of the area of climate extremes. For instance, it does not deal with risks to health caused by extreme weather events, such as heat waves (and cold spells) and flood-related health impacts, or gale wind effects on infrastructure. Heat waves in the summer of 2003 demonstrated that the related increase of mortality can be very high - several tens of thousands of additional heat-related deaths were recorded in countries of southern Europe.

The global-village effect shows that European citizens may directly experience occurrence of a natural disaster anywhere in the world. For instance, the number of citizens of some European countries killed by the 2004 tsunami in South East Asia is by far higher than the number of fatalities caused by natural disasters in these countries in Europe. 
The process of river flooding is responsible for major natural disasters in Europe. Large parts of the European continent have been hit by major floods in recent decades, including 12 flood events with the number of fatalities exceeding 100 in each. The most destructive flood event occurred in August 2002, when in five countries (Czech Republic, Germany, Austria, Hungary, and Romania) the number of flood fatalities reached 55 and the material damage soared to 20 billion Euro. Since another 1+ billion Euro event occurred in France only a month later, the year 2002 is recognized as the record-holding year in Europe in the category of highest material damage caused by river floods. Recently, in May and June 2010, destructive floods occurred in much of Europe, with high material damage in the order of billions of Euro and the number of fatalities exceeding 20 in each Poland and France.

Lugeri et al. (2010) studied spatial distribution of river flood risk in Europe for the present time, interpreting risk as composition of three elements: hazard, exposure and vulnerability. They present a topography-based flood hazard map of Europe identifying low-lying areas adjacent to rivers. This map, together with land-use data and damage-stage relationship for different land uses is used in the risk assessment, both for the whole continent and for an example region in North-East Austria. Annual average flood damage is estimated, in absolute monetary terms and in per cent of regional GDP, over NUTS 2 regions.

Kundzewicz et al. (2010) review projections for the future of river flood risk and adaptation in Europe considering a changing climate. A result from two independent model-based studies is that for approximately $30 \%$ of the area of Europe, the mean recurrence interval corresponding to what used to be the 100-year flood in the control period, is projected to decrease to below 50 years. Projections indicate that over much of Poland, Germany, Austria, Switzerland, France, and Italy the floods corresponding to the return period of 100 years in the control period are expected to become considerably more frequent in the end of the 21st century. However, over much of Russia and Scandinavia, with snowmelt being important flood generating mechanism, floods corresponding to 100year return period in the control period may become less frequent in the future. This means that for some areas the existing defences (if maintained properly) will be over-dimensioned in the future, offering sufficient protection level, while for other areas defences have to be strengthened. The present expected annual damage is projected to rise in most countries in Europe.

However, climate-driven changes in future flood frequency are projected to be complex, depending on the generating mechanism, e.g., increasing flood magnitudes where floods result from heavy rainfall and decreasing magnitudes in some areas where floods are generated by spring snowmelt. Flood risk and vulnerability tend to increase over many areas, due to a range of climatic and non-climatic impacts whose relative importance is sitespecific. It is very likely that there will be an almost ubiquitous increase in precipitation intensity due to anthropogenic climate change. Deforestation, urbanization, and reduction of wetlands diminish the available water storage capacity and increase the runoff coefficient, leading to growth in the flow amplitude and reduction of the time-to-peak of a flood triggered by assumed intense precipitation (e.g. design precipitation). Furthermore, human encroachment into unsafe areas has increased the potential for damage. Societies have become more exposed in many instances extending flood-prone areas (maladaptation). Riparians living behind a levee believe in perfect safety, so that sudden inundation caused by dike breach can be much more devastating than floods in "natural" conditions. However, much work is being done in Europe to improve flood preparedness, including the EU Floods Directive and activities of river basin commissions.

Due to the large uncertainty of climate projections, it is currently not possible to devise a rigorous, scientifically-sound, procedure for redefining design floods (e.g. 100-year floods) 
under strong non-stationarity of the changing climate and land use. The dilemma "adapt to what?" comes about. For the time being it is recommended to adjust design floods using a "climate change safety factor" approach.

Findings by Moriondo et al. (2010) demonstrate that increases in temperature and changes in precipitation, already observed and projected for the future, have a great impact on agriculture. The results of empirical downscaling of general circulation models for current climate and a future period are coupled together with a process-based crop model to quantify the impact of temperature and rainfall changes on the frequency of extreme events, with consequences to agriculture over the European Union. The work aimed at assessing the climate change impacts on agricultural yield in Europe corresponding to the global warming at the level of $+2^{\circ} \mathrm{C}$ warming. Moriondo et al. (2010) also compare the performances of different adaptation strategies to a warmer climate including advanced or delayed sowing time, shorter or longer cycle cultivar, increase in irrigation and fertilization. Crop phenology is a key attribute involved in the adaptation of crops to changing climate and no-cost adaptation options (advancement of sowing dates) are possible. Adaptation makes it possible to enhance beneficial effects of climate change (e.g. by introducing longer-cycle varieties where wetter conditions are expected in $\mathrm{a}+2^{\circ} \mathrm{C}$ climate change) as well as to reduce the negative effects (e.g. by advancing sowing time for crops grown in the Mediterranean basin).

Schelhaas et al. (2010) focus their study of fires and windstorms and of impacts on forestry on European and national scales. European forests are among the most intensively managed forests in the world. Even if only 5\% of the global forest area is located in Europe (excluding Russia), European forests' share in global round wood removals is nearly fivefold higher. Ecosystem services delivered by European forests, such as nature conservation, protection of soil, water, air and infrastructure, recreation, and carbon storage are also very important. Despite their intensive use, forest resources in Europe are growing due to afforestation; forest area has expanded, growing stock has increased and forests have become older, and these trends are expected to continue until the end of this century. Schelhaas et al. (2010) assess risk and adaptation options, evaluating the historical and projected future developments. It was demonstrated that fire risk is expected to increase, mainly as a consequence of an increase in fire hazard, while exposure (forest area) is expected to increase slightly as a consequence of active afforestation and abandonment of marginal agricultural areas. Among adaptation options to fire risk that decrease the vulnerability, a change in tree species from conifers to broadleaves has most effect. Risk for wind damage in forests is expected to increase mainly as a consequence of increase in exposure (total growing stock) and vulnerability (defined by age class and tree species distribution). Yet, projections of future wind climate are very uncertain, so that although an increase in hazard (storminess) cannot be ruled out, the robustness of this finding is not high. Adaptation options should aim to limit the increase in exposure and vulnerability, e.g. by increasing the harvest levels that curb the current build-up of growing stock and reduction of the share of old and vulnerable stands. Lowering vulnerability by decreasing the rotation length is only effective in combination with a high demand of wood.

Hinkel et al. (2010) assess risk of and adaptation to sea-level rise in the Member Countries of the European Union (EU). They show that over the 21st century sea-level rise constitutes a major risk for Europe. In the first half of this century, coastal impacts are projected to be predominantly driven by socio-economic development, being insensitive to climate-change mitigation, whose effects may come later. In the second half of the century, the consequences of sea-level rise will become more significant. Using an integrated model of coastal natural and social systems, Hinkel et al. (2010) estimate impacts, risk and 
adaptation to climate change driven sea-level rise for Europe's coastal zone without and with adaptation, such as increasing dike heights and nourishing beaches. Impacts of sealevel rise, socio-economic development, and coastal adaptation were estimated in terms of the number of people affected by annual flooding, the number of people forced to migrate due to coastal erosion, monetary damage costs and adaptation costs. The total monetary damage in coastal areas caused by flooding, salinity intrusion, land erosion and migration is projected to rise, but adaptation can reduce the number of people flooded by two orders of magnitude and the total damage costs by a factor of 4-5. Necessary adaptation costs relative to GDP are not higher than $0.05 \%$ (under the SRES A2 scenario), for any country of the EU27 with access to sea. Hence, adaptation delivers substantial benefits and looks affordable in relation to the size of the economy. However, reliable projections cannot currently be made with confidence.

\section{Economic analysis of risk and adaptation and policy issues}

Aakre et al. (2010) review the possibilities of improving the role of the public sector in adaptation to disaster risk in the EU. Basing the diagnosis on economic welfare theory and an empirical analysis of the current EU and member states' roles in managing disaster risk, they discuss how and where the public sector may intervene for managing climate variability and change. They suggest that the increasing losses caused by extreme climate events challenge the role of the public sector in financially managing today's and future disaster events. As market forces are unlikely to generate adequate adaptation to climate risk due to uncertainty and imperfect information, missing and misaligned markets and financial constraints, there is increased need for government intervention regarding risk financing options, which they analyze according to the allocation, distribution, and stabilization functions to be serviced by government.

Mechler et al. (2010b) present a selection of modelling and empirical work on economic risk and adaptation. The analysis starts with an empirical and model-based exploration of observed impacts and adaptation comparing the impact of consecutive extreme events over time in the agricultural sector. The aim of this particular approach was to determine whether adaptation has occurred in the past and whether this can be used to inform future estimates of rates of levels of adaptation. The authors find that the production of certain commodities has adapted to extreme events over time, but whether this rate can be maintained into the future is unclear. As a next step, the authors study impacts on agriculture using the general equilibrium model GRACE to assess the economic effects of a reduction in agricultural production due to droughts in Spain. An insight gained is that the degree of the scope of macroeconomic risks depends on the size of the direct risks. This highlights the importance of paying particular attention to the effect climate change may have on the spatial distribution of extreme events. Finally, Mechler et al. (2010b) discuss the management of climate variability and change by national governments using the CATSIM model assessing the fiscal consequences of natural extremes. They identify large weather-related disaster contingent liabilities, particularly in key flood hot spot countries Austria, Romania, and Hungary and find substantial disaster liabilities ("hidden disaster deficits") coupled with weak fiscal conditions to lead to substantial additional stress on the fiscal stance, and little leeway for public finances to fund other emergent projects.

Aaheim et al. (2010) assess the risks to adapt to climate change by way of an example of landslide-prone area in Norway. They demonstrate how knowledge about probabilities of natural hazards can be used to make decisions to develop areas and to control the risk 
within hazard zones. The method presented in this study is meant as a basis for ranking hazard-prone areas according to risk with a focus on economic values. It is shown that banning development in a hazard-prone area is more effective than the costly attempt of providing a satisfactory protection. The study suggests there is large uncertainty, since a relatively reliable estimate of the probability of landslides ends up in an uncertain estimate of risk. In view of this uncertainty, the development of adaptation policies to meet climate change seems a difficult challenge. Societies are not adequately adapted to the present risks and it is not clear how to make good use of the uncertain information about the possibility of an increased frequency of extreme events in the changing climate.

\section{Process-related and institutional aspects of adaptation}

McEvoy et al. (2010) suggest there is an increasing recognition that communities also need to be preparing for change that is unavoidable, partially as a consequence of anthropogenic greenhouse gases already emitted to the atmosphere. The perceived need for adaptation has also received additional impetus through the high public profile now given to the impacts of current day weather variability, particularly so, the significant economic and social costs associated with recent extreme events. However, being a relatively new focus for both research and policy communities, practical evidence of the extent, feasibility, efficiency, and cost effectiveness of potential adaptation options remains largely lacking. In response, this paper seeks to make a contribution to this evolving knowledge base by considering the theoretical underpinnings of adaptation and ultimately examining how this may translate into practice 'in the real world'. The analytical commentary, based on a bottom-up approach involving iterative engagement with key stakeholders and experts, reflects on the identification of measures that are either innovative or examples of good practice in reducing or transferring climate risks, as well as considering those 'enabling' institutional structures and processes that act to support implementation on the ground. The paper concludes by synthesising key findings in order to highlight some of the opportunities for, and barriers to, adaptation activities.

Hochrainer et al. (2010) examine the legitimacy, viability and efficiency of the European Union Solidarity Fund (EUSF) by asking whether the Fund meets its stated purpose of providing solidarity within the EU, whether it is sufficiently capitalized and whether it promotes disaster risk reduction in Europe. In examining these questions, the authors make use of modelled disaster risk throughout Europe as reported by papers in this issue. They conclude that the Solidarity Fund falls short on all three counts, and suggest a possible alternative. The EUSF could support insurance systems in Europe by, among other possible activities, capitalizing national public/private insurance programs and providing support for government risk transfer. This would leverage the Fund's capital and would overcome barriers to the provision of private sector insurance in uncertain catastrophe markets. It would also make insurance more affordable to Europe's most vulnerable communities. Finally, it would reduce the disincentives for risk reduction inherent in post-disaster assistance.

\section{Conclusions}

It is trusted that the contents of this Special Issue are relevant for research and policy communities alike, within the European Union and beyond. Already today, many regions 
and sectors in Europe are vulnerable to increasing disaster risks knowledge, resources and processes to implement cost-effective loss-reduction and risk-transfer measures. We hope that the strong focus on the concept of risk, visible in contributions to this Special Issue, may be important for local stakeholders and national authorities of European states alike to raise awareness to exposures to current and future risks as well as to help adapt more effectively to a changing extreme event regime. While difficult, risk-based adaptation planning seems important and timely.

The importance of such research has recently been underlined by the Stern Review (Stern 2007), where an extended cost-benefit calculation was conducted and the benefits were compared in terms of avoided impacts of unabated climate change over the next two centuries to the costs of stabilizing greenhouse gas concentrations worldwide. Furthermore, in the recent IPCC report (Parry et al. 2007) an increased focus on risk management for climate change adaptation was suggested, and the climate change modelling community is gradually embracing a more risk-based focus. Finally, as regards policy, the EU White Paper on Adaptation (CEC 2009) has underlined the policy relevance of climate change impact and adaptation research and identified managing disaster risk as a priority area for adaptation action. Where current knowledge is sufficient, adaptation strategies should be developed in order to identify optimal resource allocation and efficient resource use for guiding EU action through sectoral and other policies. Where significant knowledge gaps exist, community research, exchange of information, and preparatory action may further contribute to expanding the knowledge base and managing uncertainty. The work reported in this Special Issue should be understood as a contribution to the emerging discussion on adaptation and an exploration of the scale and scope of knowledge gaps.

\section{References}

Aaheim A, Romstad B, Sælen H (2010) Assessment of risks for adaptation to climate change: the case of land-slides. Mitig Adapt Strateg Glob Change 15(7):763-778

Aakre S, Banaszak I, Mechler R, Rübbelke D, Wreford A, Kalirai H (2010) Financial adaptation to disaster risk in the European Union: Improving roles for the public sector. Mitig Adapt Strateg Glob Change 15 (7):721-736

CEC (Commission of the European Communities) (2009) Adapting to climate change: towards a European framework for action. White Paper. COM(2009) 147 final, Brussels, 1.4.2009

Hinkel J, Nicholls RJ, Vafeidis AT, Tol RSJ, Avagianou T (2010) Assessing risk of and adaptation to sea-level rise in the European Union: an application of DIVA. Mitig Adapt Strateg Glob Change 15(7):703-719

Hochrainer S, Linnerooth-Bayer J, Mechler R (2010) Adaptation and risk financing. The European Union Solidarity Fund. Its legitimacy, viability and efficiency. Mitig Adapt Strateg Glob Change 15(7):797-810

Kundzewicz ZW, Lugeri N, Dankers R, Hirabayashi Y, Döll P, Pińskwar I, Dysarz T, Hochrainer S, Matczak P (2010) Assessing river flood risk and adaptation - review of projections for the future. Mitig Adapt Strateg Glob Change 15(7):641-656

Lugeri N, Kundzewicz ZW, Genovese E, Hochrainer S, Radziejewski M (2010) River flood risk and adaptation in Europe - assessment of the present status. Mitig Adapt Strateg Glob Change 15(7):621-639

McEvoy D, Matczak P, Banaszak I, Chorynski A (2010) Framing adaptation to climate-related extreme events. Mitig Adapt Strateg Glob Change 15(7):779-795

Mechler R, Hochrainer S, Aaheim A, Kundzewicz Z, Lugeri N, Moriondo M, Sælen H, Bindi M, Banaszak I, Chorynski A, Genovese E, Kalirai H, Linnerooth-Bayer J, Lavalle C, McEvoy D, Matczak P, Radziejewski M, Rübbelke D, Schelhaas M-J, Szwed M, Wreford A (2010a) A risk management approach for assessing adaptation to changing flood and drought risks in Europe. In: Hulme M, Neufeldt $\mathrm{H}$ (eds) Making climate change work for us: European perspectives on adaptation and mitigation strategies. Cambridge University Press, Cambridge, pp 200-229

Mechler R, Hochrainer S, Aaheim A, Sælen H, Wreford A (2010b) Modelling economic impacts and adaptation to extreme events: Insights from European case studies. Mitig Adapt Strateg Glob Change 15(7):737-762 
Mills E (2005) Insurance in a climate of change. Science 309:1040-1044

Moriondo M, Bindi M, Kundzewicz ZW, A, Szwed M, Chorynski, A, Matczak P, Radziejewski M, McEvoy D, Wreford A (2010) Impact and adaptation opportunities for European agriculture in response to climatic change and variability. Mitig Adapt Strateg Glob Change 15(7):657-679

Parry ML, Canziani OF, Palutikof JP, van der Linden PJ, Hanson CE (eds) (2007) Climate Change 2007: impacts, adaptation and vulnerability. Contribution of Working Group II to the Fourth Assessment Report of the Intergovernmental Panel on Climate Change. Cambridge University Press, Cambridge, UK, $976 \mathrm{pp}$

Schelhaas M-J, Hengeveld G, Moriondo M, Reinds GJ, Kundzewicz ZW, ter Maat H, Bindi M (2010) Assessing risk and adaptation options to fires and windstorms in European forestry. Mitig Adapt Strateg Glob Change 15(7):681-701

Stern N (2007) The economics of climate change. Cambridge University Press, Cambridge, UK 